$63^{\text {ème }}$ Congrès de la SFCO, 02033 (2015)

DOI:10.1051/sfco/20156302033

(C) Owned by the authors, published by EDP Sciences, 2015

\title{
COMMUNICATION
}

\section{Cas d'un granulome ulcéré éosinophile post traumatique chez un enfant de 3 ans}

Pannérec V, Fricain J-C

CHU Bordeaux, 1 place Amélie Raba-Léon, 33000 Bordeaux

Le granulome éosinophile ulcéré post traumatique (GEUT) est une lésion bénigne rare de la muqueuse buccale siégeant principalement sur la langue (Shen 2013). Il peut être diagnostiqué à n'importe quel âge. Chez les enfants la forme clinique la plus fréquente est la maladie de Riga-Fede (Marszalek 2011). Il s'agit d'une affection bénigne de la muqueuse buccale, souvent causée par des traumatismes dentaires (Graillon 2013), et peu décrite dans la littérature elle peut parfois être révélatrice de troubles dysautonomiques ou neuropsychiques (Marie 2012). Le cas d'un GEUT évoquant un carcinome épidermoide est rapporté.

Un enfant de 3 ans sans antécédents médicaux ou chirurgicaux était adressé pour avis concernant une lésion suspecte d'apparition rapide, peu symptomatique altérant l'alimentation. L'examen clinique révélait une excroissance de $3 \mathrm{~cm}$ de diamètre sur le bord de langue gauche. Il s'agissait d'un nodule ulcéré avec des berges surélevées et irrégulières. Les aires ganglionnaires étaient libres. Deux biopsies profondes ont été réalisées. L'aspect histologique était en faveur d’un GEUT avec une surface ulcérée recouverte d'une pseudomembrane fibrineuse et un chorion présentant un infiltrat inflammatoire polymorphe dense, riche en éosinophiles. Le facteur traumatique n'ayant pas été identifié, une simple surveillance a été instaurée en première intention. A un mois, la masse avait diminué. Trois semaines après la lésion avait disparu. Le contrôle à 6 mois n’a pas montré de récidive. Nous n’avons pas retrouvé les troubles neuropsychiques ou dysautonomiques sous-jacents rapportés dans certaines observations.

Le GEUT est une ulcération guérissant lentement, parfois symptomatique avec des marges surélevées, indurées, imitant un carcinome épidermoide (Chatzistamou 2012). Les facteurs étiologiques et la pathogenèse font encore débat mais ces lésions seraient souvent en rapport avec une irritation traumatique (Shen 2013). Le GEUT doit être connu des spécialités médicales en rapport avec la cavité buccale en raison du risque de confusion avec une lésion maligne qui peut angoisser à tort le patient et sa famille alors qu'une prise en charge rapide associée à une reprise de l'alimentation évitent tout retentissement somatique.

Nom et adresse du conférencier

\section{Virginie PANNEREC}

\section{CHU Bordeaux}

1 place Amélie Raba-Léon

33000 Bordeaux (France)

pnnrcvrgn83@aol.fr

This is an Open Access article distributed under the terms of the Creative Commons Attribution License 4.0, which permits unrestricted use, distribution, and reproduction in any medium, provided the original work is properly cited. 